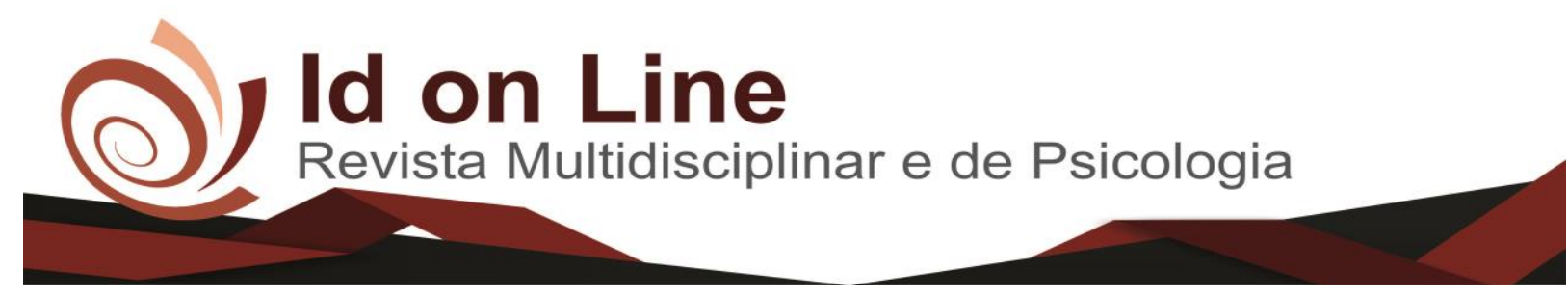

Comment

\title{
Um novo olhar para a Matemática: Novos métodos de ensino
}

\author{
Edjani Maria da silva ${ }^{l}$; Cicera Raquel de Melo Viana ${ }^{2}$
}

\begin{abstract}
Resumo: Este artigo tem por objetivo mostrar o quanto o Ensino da Matemática vem evoluindo nos últimos tempos, fazendo um comparativo da matemática de antes com a matemática da atualidade. Trazendo à tona novas formas e novas possibilidades para ensinar a matemática assim sendo mais bem aplicada e melhor entendida. Dentro dessa perspectiva entende-se que a matemática está presente em toda a parte e em todos os campos de conhecimento, porém muitos têm dificuldade em entendê-la e principalmente em apreciá-la, dificultando seu uso como ferramenta de auxílio fundamental para a formação de um cidadão crítico e reflexivo.
\end{abstract}

Palavras-chave: Ensino da Matemática, Novas Possibilidades, Conhecimento, Ferramenta de auxílio.

\section{A New Look at Mathematics: New Teaching Methods}

\begin{abstract}
This article aims to show how much Mathematics Teaching has evolved in recent times, showing a comparative of the mathematics of before with the mathematics of the present time. Bringing forth new forms and new possibilities to teach mathematics so that it is better applied and better understood. Within this perspective it is understood that mathematics is present everywhere and in all fields of knowledge, but many have difficulty in understanding it and especially in appreciating it, making it difficult to use as a fundamental aid tool for the formation of a critical and reflective citizen.
\end{abstract}

Keywords: Mathematics Teaching, New Possibilities, Knowledge, Aid Tool.

\section{Introdução}

De acordo com a história, a Matemática fora concebida tal qual uma ciência hermética e desinteressante. Em muitos casos, são comuns relatos de experiências traumáticas quando o assunto são questões que envolvem tal ciência. Vindo a ser considerada uma "ânsia escolar", por esse motivo optou-se pelo tema Novo olhar Matemático, para os métodos de ensino, dessa forma a pesquisa tende a comprovar que é importante um novo olhar para a matemática, envolvendo a interdisciplinaridade e as novas metodologias ativas, ressaltando reflexões na prática docente.

\footnotetext{
${ }^{1}$ Faculdade de Ciências Humanas do Sertão central - FACHUSC. Email: edjanidaiane24@ hotmail.com

${ }^{2}$ Graduada no Curso de Ciência com Hab em Biologia com Esp. em Turismo e Meio Ambiente na Universidade Regional do Cariri URCA/Crato-CE, Graduada em Licenciatura em Física na Faculdade Grande Fortaleza-FGF/Fortaleza-CE com Esp. em Ensino da Física na Universidade Federal Rural de Pernambuco - UFRPE/Recife-PE.
} 
Essa disciplina é fonte de grande receio e desprendimento nos anos iniciais do Ensino Fundamental e para o Ensino Médio.

O primeiro questionamento que se vem em mente é. Como educar a criança a pensar matematicamente se, nos seus períodos de escola, o professor obteve uma formação mais voltada para o aprendizado das operações matemáticas? Os cursos de Pedagogia, nem sempre cultivam uma carga horária adequada ao campo da Educação Matemática, o que por vezes vem criando nessa disciplina uma fonte de grande receio e desinteresse para alunos nos anos iniciais do Ensino Fundamental. "O aprendizado com a Matemática nem sempre foi bom”. Tais experiências que já foram vivenciadas por inúmeros professores enquanto foram alunos, de pensar e resolver problemas matemáticos.

No entanto muito está sendo feito em relação a novos olhares, frisando que a matemática é para todos e que se pode sim aprender de forma natural e divertida. E que por trás de toda teoria, tem uma forma nova prática de provar que podemos sim envolver e encantar os educandos, para isso somente é preciso buscar inovar. É fundamental aproveitar todos os momentos e oportunidades que se é permitido. A matemática é uma ciência que não é comandada pelo ser humano, segue a máxima: "Foi matematicamente comprovado", que insinua que há ainda muito ainda a ser descoberto. Trata-se da "ciência mãe" de todas as outras, e de grande importância na vida das pessoas de maneira direta ou indireta.

A Matemática está presente em toda a parte e em todos os campos de conhecimento, porém muitos têm problemas em entendê-la e em adaptá-la a realidade, dificultando seu uso como ferramenta de trabalho para a formação de um cidadão reflexivo e crítico. Fundamentado nisso, usar novos métodos de ensino é o primeiro passo para redescobrir o encanto singular dessa disciplina que geralmente é discriminada nas escolas, tanto pelos alunos, como por professores.

\section{Desenvolvimento}

Antes mesmo de ponderar ou falar sobre qualquer fato que esteja atrelado ao campo da matemática, é necessário que se busque entender como surgiu essa jornada histórica da matemática. MIORIN (1998) nos orienta que, antes das primeiras noções matemáticas, o homem sobrevivia da caça, de pescados e da coleta de frutos e sementes. Não havia controle sobre essa produção. Havia sim, uma dependência sobre a natureza. Com a agricultura, 
aconteceu a domesticação e criação de animais e, consequentemente a fabricação de novos instrumentos e armas.

Surgem as primeiras representações esquemáticas e geométricas com suas simetrias e congruências. Não apenas os conhecimentos geométricos, mas também os numéricos começaram a surgir (MIORIN, 1998).

Percebe se que varias áreas do conhecimento surgiu de questionamentos e necessidades que foram brotando ao longo do tempo. A matemática, mais especificamente, partir-se de questões imprescindíveis para a sociedade, no entanto, partiu-se para um ponto a desenvolver uma matemática legítima e limitada. Hoje as novas tecnologias vêm sendo necessárias e por decorrência se expandindo. Contudo, pode-se perceber que a matemática inúmeras vezes é tida hoje como uma disciplina complexa e sem semelhança com o dia-a-dia dos educando. Eles desconhecem a real seriedade dessa ciência mãe que é a matemática e sua suma importância em seu surgimento, tanto em outras áreas tanto em suas inúmeras aplicações (MESTRINER, 2007).

Estudar Matemática é basicamente analisar e apontar uma determinada forma de pensar e agir matematicamente, desenvolvendo outras formas de raciocinar. É por isso que não aprende-se Matemática da mesma forma ou jeito que se fez ontem ou se fará amanhã. Ponderamos que grande parte do fracasso escolar é resultado do desconhecimento deste fato. Apesar de que essa realidade não é exclusiva dessa ciência .

O descontentamento nessa disciplina tornou-se motivo de grande apreensão para o sistema educativo, o qual não deu ainda respostas concretas e ativas para o solucionamento deste problema. De acordo com declarações que ouvimos com frequência de gerações anteriores, a antipatia pela Matemática já existia nesses tempos, embora se admita hoje um significado diferente. Frequentemente escutam-se relatos de pessoas, sejam jovens ou adultos que se manifestam claramente sua visão negativa diante a Matemática, possivelmente relacionada com uma equivocada incapacidade para as atividades matemáticas bem elementares do cotidiano ou próximo a atividades profissionais.

Nas escolas o mesmo ocorre, de tal modo que docentes e pais já estão acostumados a atitudes apáticas e desinteressados acerca da disciplina referida. Propriamente, com a redução de comparecimento nas instituições, sendo elas o ponto de iniciação da prática educativa, sendo perceptivo o total desinteresse do alunado alguns, encontram-se inteiramente alienados de toda e qualquer coisa que envolva a matemática, ali desenvolvida. Consisti a estes costumes a imagem da pouca estima em inclusão a esta disciplina? Consisti em uma dificuldade de 
entendimento? De onde surgiu e como se desenvolveu? Parece-nos que, efetivamente, o ensino aprendizagem da Matemática atravessa uma intensa crise que em nível das escolas. Segundo LUCKESI o nosso senso comum, quanto a vida escolar, não tem sido de avaliadores, basta lembrar que:

$\mathrm{O}$ ato de examinar se caracteriza pela classificação e seletividade;

$\mathrm{O}$ ato de avaliar se caracteriza pelo diagnóstico e pela inclusão.

LUCKESI explica que o educando não vai para a escola para ser submetido a um processo seletivo; e, sim, para aprender. Interessa, portanto, o sistema escolar em que o educando aprenda, e não aquele em que ele seja meramente reprovado.

Os educadores precisam investir na avaliação, pois, em geral, repetem o que aconteceu com eles. Ou seja, "fomos examinados por nossos professores, através de exames escolares, agora somos examinadores de nossos alunos, utilizando-nos dos mesmos instrumentos. "'

O que significa, então, “aprender a avaliar”? Constituem aprender os conceitos teóricos sobre avaliação, mas estudar também como praticar essa forma de avaliação, em atos do dia-adia escolar. Mas de que forma podemos cuidar em aprender a avaliar a própria aprendizagem de nossos alunos, incluindo-se aí, a nossa auto avaliação como educadores e avaliadores? Questiona-se LUCKESI. Em segundo lugar, mostra o teórico, que devemos observar se estamos satisfeitos (ou não) com todos os resultados advindos da aprendizagem de nossos alunos. Caso os resultados não sejam tidos como satisfatórios, devemos compreender o que estaria por trás dessa defasagem. O que inclui nossa ação pedagógica.

Para Matos e Valente (2007, p. 28) há pelo menos duas razões para um olhar novo para a Matemática:

\footnotetext{
Em primeiro lugar, o grande desenvolvimento da Matemática pura em nossa época. Em seguida, existe o fato de que, o pensamento crítico científico encontra-se cada vez mais tributário das fórmulas matemáticas, numa era em que praticamente todos tem necessidade de um número cada vez maior de pesquisadores e de todas as disciplinas.
}

Deseja-se para o ensino da Matemática, um tríplice papel. Pretendia-se segundo Matos e Valente (2007) um papel mais formativo que, envolvesse as capacidades mentais e intelectuais do educando, um papel de maior e que o prepare para a inserção na vida quotidiana e profissional. Na concepção de Valente (2007, p. 80) "para que um sistema de ensino exista, isto é, para que o ensino seja possível, é preciso que haja compatibilidade do sistema com o meio onde o educando está inserido." Tal inquietação com respeito ao aprendizado da Matemática, 
significa que não se pode limitar a escrever na lousa o simbolismo da disciplina, pois que, os educandos, apenas aprenderiam as fórmulas, ou as teorias abstratas, que estão muito fora de sua aplicabilidade.

\section{Formas de se ensinar Matemática: como criar um ambiente de aprendizagem bom para todos?}

Cada vez mais aparecem novas formas de ensinar nas escolas. Infelizmente, algumas delas ainda não estão numa forma de fazer com que os alunos se sintam estimulados ao aprendizado. Acreditamos no entretenimento como uma maneira mais adequada de motivar ao aprendizado. Por isso, apresentamos algumas dicas criativas para ensinar matemática a uma criança.

\section{Doces sobre a mesa}

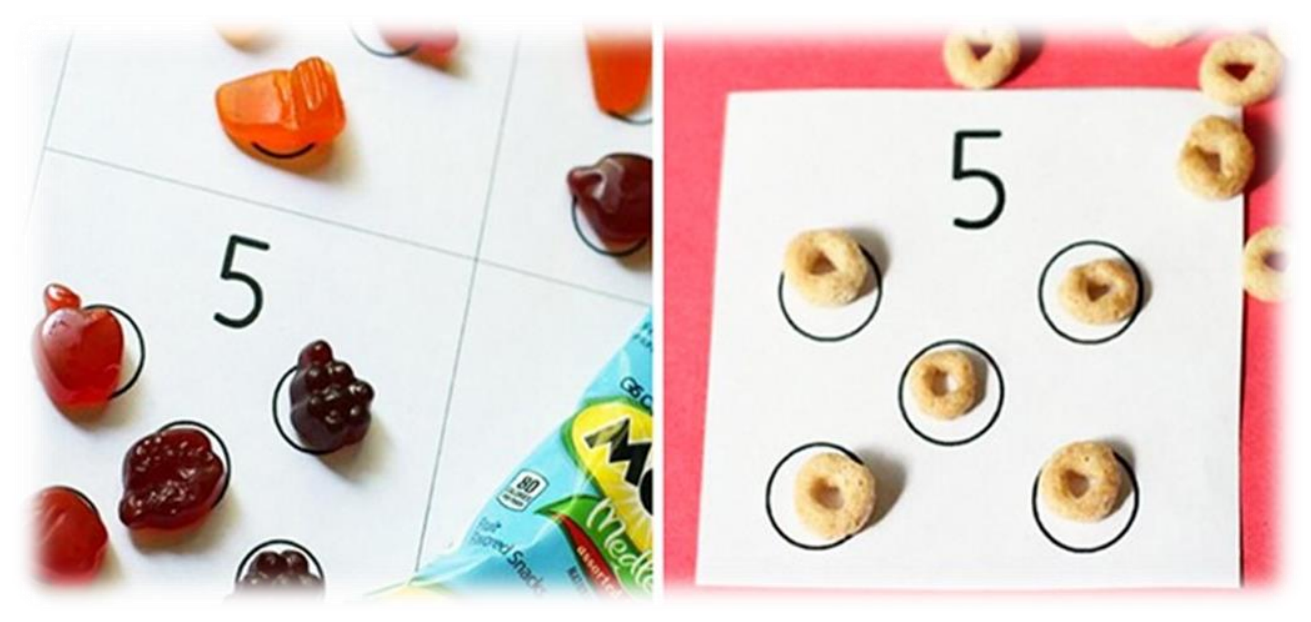

Trata-se de um tipo de "aula" interessante quanto a motivação. Prepare algumas folhas de papel em diferentes quantidades de círculos nelas desenhados. Coloque alguns bombons ou qualquer outro alimento - dentro dos círculos. Faça isso com diferentes números. Mostre como cada número é 'fisicamente'. 


\section{Pausa Musical}
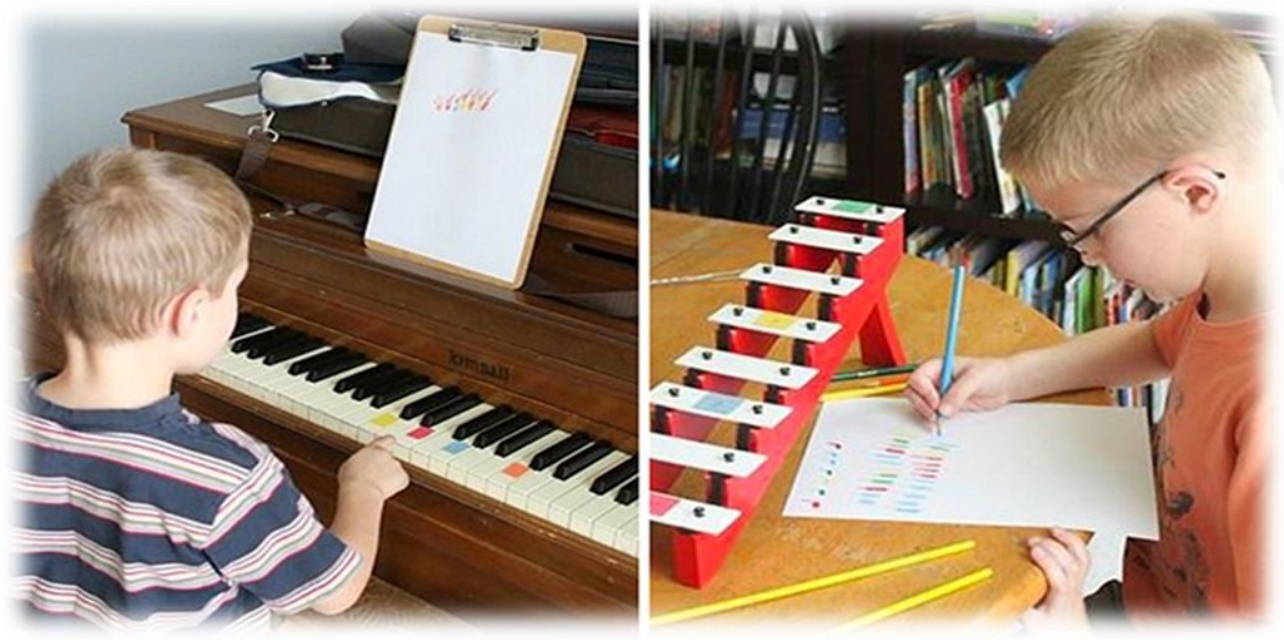

Uma ótima idéia para quem gosta de música. Atribua a cada tecla um determinado número (use uma fita adesiva) e solicite aos alunos que componham uma música pequena.

\section{Mais Ou Menos?}

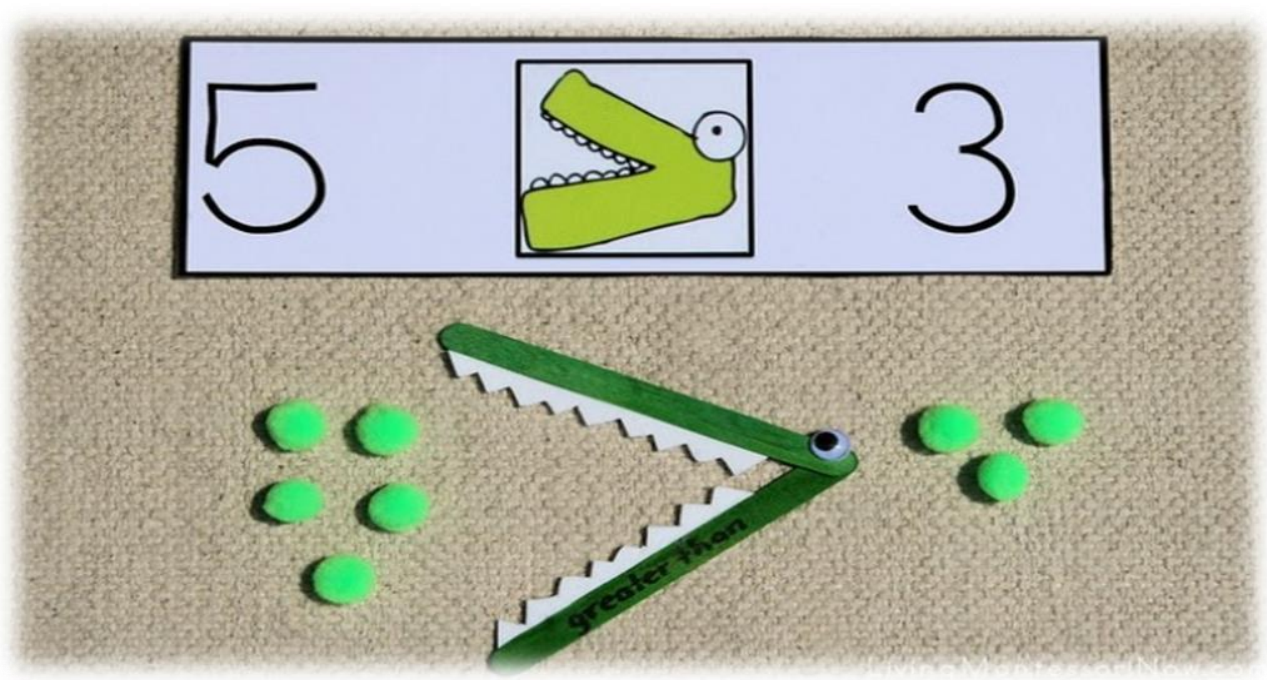


Este divertido jacaré (feito com palitos de sorvete) ensina o seu filho um pouco sobre os símbolos 'maior' e 'menor'. Fazendo com que ele aprenda de uma forma divertida os primeiros números, possibilitando os distinguir os números maiores e menores.

\section{Aprendendo a contar com balinhas}

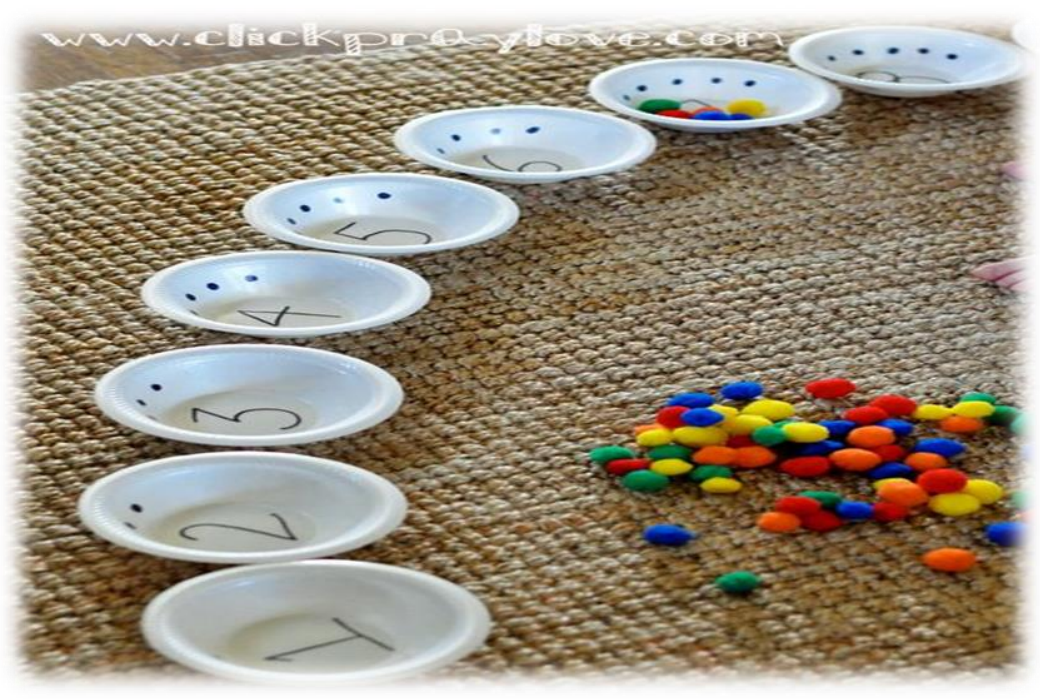

Este método é uma excelente forma de introduzir a matemática na vida dos pequenos, sendo ele fácil, gostoso e divertido, sem contar que ao final da brincadeira os pequenos terão aprendido e se divertido aprendendo a contar quantas balinhas continham em cada recipiente.

\section{Aprendendo com o Lego}

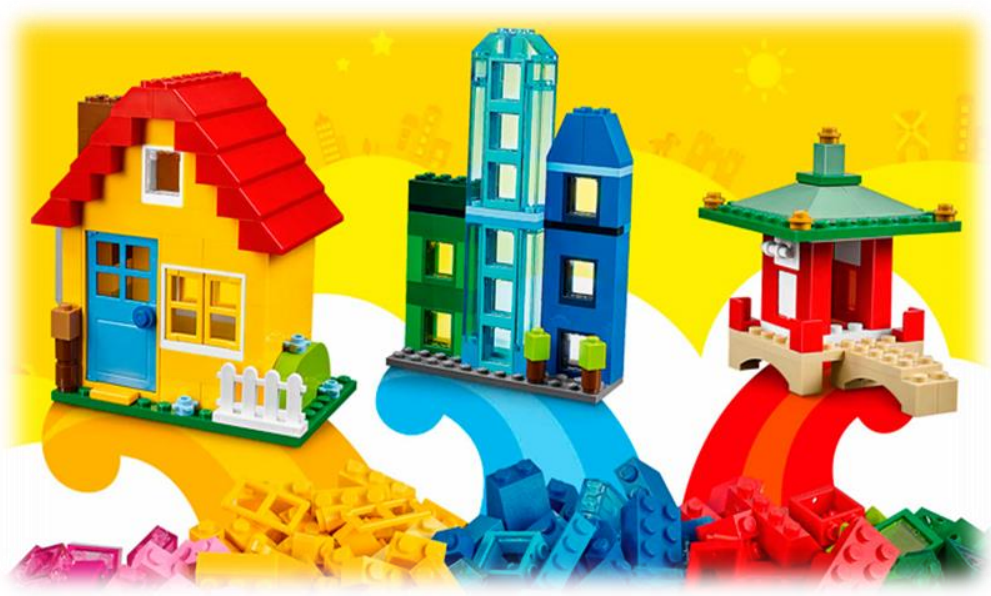


Acima de tudo, o Lego é um jogo de montagem que estimula a criatividade de crianças e adultos. Além de estimular e trabalhar a lógica. Ao realizar as montagens, somos levados a pensar sobre as regras de encaixe, de simetria, de arquitetura e de lógica. O Lego ainda contribui no desenvolvimento da imaginação e da noção de espaço em jovens, crianças e bebês. É muito mais do que um mero jogo bobo - aliás, jogos bobos não faltam nas lojas hoje em dia!O brinquedo contribui intensamente na construção das capacidades mentais. Ele possui benefícios pedagógicos indiscutíveis, e por isso alguns professores decidiram utilizá-los em sala de aula para enriquecer as práticas e promover a contextualização de algumas disciplinas. Existem até alguns livros didáticos que recomendam a sua utilização!

\section{Ensino Otimizado}

Segundo pesquisadores, a avaliação formativa, quando as crianças são deixadas mais livres para tentar resolver problemas, aumenta se o domínio de conceitos fundamentais de matemática. Trata-se de uma nova abordagem que permite aos professores atenderem melhor às necessidades das crianças e jovens, além de evitar que se retenha aqueles que já estão prontos para avançar. Isso otimiza, de forma eficiente, aqueles alunos que ainda estão com mais dificuldades de aprendizado.

\section{A Informática na Educação}

O uso da tecnologia está cada vez mais presente em nosso cotidiano. Porém, na área da educação ainda parece um processo muito lento. Na disciplina de matemática, o uso das novas tecnologias se torna um método didático importante nos dias atuais. Há diversos recursos bem mais facilitadores na resolução de cálculos. As planilhas eletrônicas e os processadores de texto e criação de gráficos à partir de bancos de dados, são de grande riqueza (SANCHO, 2006). O uso do computador favorece a comunicação interpessoal e a construção colaborativa do conhecimento. 


\section{Metodologia}

Optou-se pela pesquisa bibliográfica, buscando teorias fundamentadas em idéias de autores que correspondem ao surgimento de formas de ressignificar o ensino-aprendizagem da Matemática. Fez-se um estudo bibliográfico para compreender de que forma a educação matemática avançou em vários períodos da história, para um rápido diagnóstico do surgimento de novas idéias para se ensinar a matemática, de forma que seja mais significativa aos alunos.

Assim sendo, o objetivo foi conhecer a realidade de alunos sobre a forma como as aulas de matemática acontecem na prática e, sobre interesse em aprender matemática para construir outras possibilidades de avanços no ensino aprendizagem.

\section{Considerações Finais}

Tem-se a matemática como uma ferramenta importante na vida de todas as pessoas, contudo ela necessita ser compreendida e englobada a vida do aluno de matemática já nos anos iniciais da vida escolar. O que causa muita apreensão, porém, é que a educação para a matemática, muitas vezes, não tem o rigor e capacidade de se assimilar com a realidade do aluno, implicando em que o mesmo passe por despercebido a real importância de aprender matemática para a vida. E é nessa ótica que a educação matemática se manteve por muito tempo, e está ainda continua em muitos locais, desvinculada da realidade dos alunos, que não compreendem a aplicabilidade em seu cotidiano. Portanto, a matemática torna-se abstrata e sem sentido. Não motiva.

Apesar disso, existem formas de deixar à matemática prazerosa e aplicativa a vida dos educandos. Nesse sentido, as didáticas mais ativas e a interdisciplinaridade precisam ser envolvidas no processo de ensino da matemática. Conclui-se que a matemática carece de ser apreciada e de representar significação aos alunos. Os professores são a partida, pois deles que, sobretudo, provém às mudanças comportamentais, tanto na metodologia que deverão utilizar quanto na percepção da real importância desta disciplina na vida dos alunos. Acredita-se numa educação que seja inovadora, que demonstre sua beleza e necessária aplicação na vida de todas as pessoas.

O futuro da Educação, especialmente das Matemáticas não depende de revisões de conteúdo, mas do significado percebido desta, na vida prática cotidiana. Tampouco é 
dependente de uma metodologia mágica. Mas de um professor que se proponha a assumir sua nova posição, reconhecendo-se um companheiro de jornada junto aos seus estudantes, na busca do conhecimento e das lógicas matemáticas nele existentes.

\section{Referências}

BAGESTÃO, Adriane Lenhard. Uso da informática na matemática. 2012. 51 p. Monografia de Licenciatura em Matemática. Faculdade de Itapiranga, Itapiranga, SC, 2012.

D’AMBRÓSIO, Ubiratan. Educação matemática: da teoria á prática. Campinas, SP: Papirus, 1996, p. 17-28. Coleção Perspectivas em Educação Matemática.

GANDIN, Danilo. Planejamento: Como Prática Educativa. 8. ed. São Paulo: Loyola, 2007.

GURGEL, Célia Margutti do Amaral. Em busca da melhoria da qualidade do ensino de Ciências e Matemática: ações e revelações. Minas Gerais, 1995.

LUCKESI, Carlos Cipriano. Avaliação da aprendizagem escolar: estudos e proposições. São Paulo: Cortez, 2011.

MIORIM, Maria Ângela. Introdução à história da matemática. São Paulo: Atual, 1998.

MUNIZ C. A. Brincar e jogar: enlaces teóricos e metodológicos no campo da educação matemática. Belo Horizonte: Autêntica Editora, 2010

SANT'ANNA, Ilsa Martins. Por que avaliar?: como avaliar? Critérios e instrumentos. 13. ed. Rio de Janeiro: Vozes, 2009.

SELBACH, Simone et al. Matemática e Didática. Rio de Janeiro: Vozes, 2010.

VASCONCELLOS, Celso dos Santos. Planejamento: Projeto de ensino- aprendizagem e Projeto político - pedagógico. 17. ed. v. 1. São Paulo: Libertar Editora, 2007.

Como citar este artigo (Formato ABNT):

SILVA, Edjani Maria da; VIANA, Cícera Raquel de M. Um olhar para a matemática: novos métodos de ensino. Id on Line Revista Multidisciplinar e de Psicologia, 2017, vol.11, n.38, p.749-758. ISSN: 1981-1179. 